\title{
PRACTICE MANAGER WINS
}

NATIONAL AWARD

Joanne Holroyd, Practice

Manager at

Meltham

Dental Care in

Joanne (right) receiving

her award from Lyn Oliver, ILM business manager

Holmfirth, West

Yorkshire has been presented

with the Learner of the Year for England

award by the Institute of Leadership \&

Management (ILM).

The national award celebrates the

achievements of practising managers, employers, training providers and learners who have accomplished outstanding results through innovative approaches to leadership and management.

Joanne said, 'Before I started the ILM qualification I often felt like a rabbit caught in headlights. Completing the ILM management qualification gave me the confidence I needed to introduce new ideas and initiatives to the practice.'

Joanne completed her qualification at ILM's accredited centre, UMD Professional in Surrey.

\section{ACCREDITATION FOR COURSE IN} DENTAL PRACTICE MANAGEMENT The partners at The Dentistry Business were celebrating earlier this month, when six months of hard work resulted in their Level 4 and Level 7 courses in Dental Practice Management gaining accreditation from the University of Chester.

The Professional Certificate, scheduled to start in May 2010, is designed for dental practice staff who are either already practice managers or who aspire to such a position. It will provide the theoretical and practical tools required to support a practice owner in the operation of a single or multi-site practice and provide an in-depth understanding of the mechanics of running a business and the techniques required to address the many problems that occur at both strategic and tactical levels.

The course comprises three modules which will run over ten full-day sessions. A successful pass will attract 60 credits that are transferable to any university or college for future studies, if desired.

The Postgraduate Certificate in the Mastery of Dental Practice Management course will be available from October 2010 and is designed for dentists and experienced practice managers.

For more information contact Sim Goldblum on 01619285995 or visit www.thedentistrybusiness.com.

\section{NEW SCHOLARSHIP LAUNCHED}

BDA Education has announced the creation of the 'Ann Felton Scholarship'. This is an opportunity for dental nurses to be allocated a free place on BDA Education's online Oral Health Education (OHE) course.

The OHE course is worth $£ 595$ and leads to the NEBDN Certificate in OHE. This scholarship has been developed in recognition of the outstanding contribution made by Ann Felton to the dental profession and to the careers of dental nurses across the county. In 2000, Ann formed OHESouthwest, which was to become one of the top OHE courses in the country. She was also elected Secretary of the BDHA South West/ South Wales Regional Group. In Ann's later years, despite a long battle with cancer, she carried on teaching, wrote a course textbook, and developed the online course with the BDA. Ann Felton sadly passed away in 2007 and the OHE Scholarship has been launched in her honour.

In order to be eligible for this prize, you will need to explain, using a maximum of 250 words, how you would use the OHE Scholarship to advance your career.

To apply for the OHE Scholarship, simply complete the application form by 2 July at this link: www.bda.org/ohe/scholarship, and answer the following question: 'Explain, using a maximum of 250 words, how you would use the OHE Scholarship to advance your career.'

For more information on the Oral Health Education course, as well as other courses run by BDA Education, go to: www.bda.org/dcps/. 